\title{
Vulnerabilidad urbana en asentamientos informales de Ushuaia. Una aproximación analítico-comparativa desde la mirada de distintos actores
}

\section{Lucía Fank}

Arquitecta (UNC). Doctoranda en Estudios Urbanos y Regionales BAUHAUS UNIVERSITÄT- UNC Córdoba. Becaria doctoral CONICET 2015-2020. Finalizando Maestría en "Hábitat y Pobreza Urbana en América Latina” (UBA). Cuenta con experiencia en docencia de grado y posgrado. Integrante del Grupo de Trabajo CLACSO Fronteras, regionalización y globalización y de distintos proyectos de investigación (PIP CONICET 2017- 2020: "Valorización de la naturaleza y nuevas territorialidades en Patagonia", PICT 2015 3734: "Territorialidades en conflicto. Huella ecológica y eco espacio en Patagonia sur, Cuyo y NOA", Secyt Consolidar: "Reestructuración productiva, Industria y urbanización").

Instituto de Humanidades IDH- UNC, Córdoba; BAUHAUS UNIVERSITÄT, Weimar.

lucia.fank@gmail.com

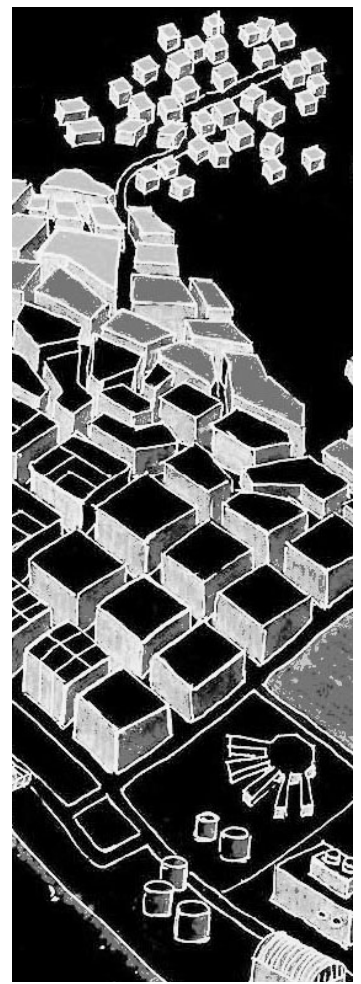

http://dx.doi.org/10.30972/crn.30304928 


\section{Vulnerabilidad urbana en asentamientos informales de Ushuaia. Una aproximación analítico-comparativa desde la mirada de distintos actores}

\section{Resumen}

Existen múltiples desventajas asociadas a la informalidad urbana que inciden negativamente en las condiciones de vida de los habitantes y generan distintas situaciones de vulnerabilidad. El presente trabajo propone definir el grado y la composición de la vulnerabilidad urbana en asentamientos informales de la ciudad de Ushuaia, Argentina, desde un enfoque comparativo y multi-actoral. Para ello se aplica un índice que incorpora la integralidad de las problemáticas existentes, ponderadas según tres grupos de actores: referentes barriales, gobierno local y la academia especializada. Los resultados muestran que el nivel de vulnerabilidad urbana es mayor en asentamientos nuevos que en el resto de la ciudad, y que su composición varía según el caso y la mirada de los distintos actores. El análisis presentado constituye un insumo básico para la formulación de políticas públicas adecuadas e integrales para la atención de la informalidad urbana, y permite establecer criterios de priorización en futuros abordajes territoriales.

\section{Palabras clave}

Informalidad; vulnerabilidad urbana; índice multidimensional; perspectiva comparativa.

\section{Urban vulnerability in informal settlements of Ushuaia. An analytical-comparative approach from different actors perspectives}

\begin{abstract}
There are multiple disadvantages associated with urban informality that negatively affect inhabitants living conditions, leading to numerous vulnerability situations. This research aims to define urban vulnerability degree and composition in informal settlements of Ushuaia, Argentina, from a comparative and multi-actor approach. For this, an index is applied to incorporate existing problems comprehensiveness, weighted according to three groups of actors: neighborhood referents, local government and the specialized academy. Results show that urban vulnerability level is higher in new settlements than in the rest of the city, and that its composition varies according to the case and the perspective of the different actors. The analysis presented constitutes a basic input for adequate and comprehensive public policies formulation to deal with urban informality, allowing to establish prioritization criteria establishment in future territorial approaches.
\end{abstract}

\section{Keywords}

Informality; urban vulnerability; multidimensional index; comparative perspective.

\section{Vulnerabilidade urbana em assentamentos informais de Ushuaia. Uma abordagem analítica-comparativa da vista de diferentes atores}

\section{Resumo}

Existem várias desvantagens associadas à informalidade urbana que incidem negativamente nas condições de vida dos habitantes, gerando distintas situações de vulnerabilidade. O presente trabalho propõe definir o grau e a composição da vulnerabilidade urbana em assentamentos informais na cidade de Ushuaia, Argentina, a partir de uma abordagem comparativa e multi-atoral. Para isso é aplicado um índice que incorpora a integralidade dos problemas existentes, ponderados de acordo com três grupos de atores: referentes de bairro, governo local e academia especializada. Os resultados mostram que o nível de vulnerabilidade urbana é maior nos novos assentamentos do que no restante da cidade e que sua composição varia de acordo com o caso e a perspectiva dos diferentes atores. A análise apresentada constitui um insumo básico para a formulação de políticas públicas adequadas e abrangentes de atenção à informalidade urbana, e permite estabelecer critérios de priorização em futuras abordagens territoriais.

\section{Palavras chave}

Informalidade; vulnerabilidade urbana; índice multidimensional; perspectiva comparativa. 


\section{Introducción}

La informalidad urbana es un fenómeno característico y creciente en las ciudades latinoamericanas (FERnANDES, 2016). Refiere a la producción del hábitat fuera de los canales formales, y normalmente son los propios usuarios quienes la llevan a cabo, material e inmaterialmente (Jaramillo, 2008). Su crecimiento sostenido en las últimas cuatro décadas se vincula tanto con dinámicas macroeconómicas como con el funcionamiento del mercado inmobiliario y las políticas que regulan, producen y comercializan el suelo y la vivienda (AвRAmo, 2012). Resultado de la combinación de estas políticas en favor de la mercantilización de los bienes y servicios urbanos (Pírez, 2016), un gran número de actores sociales han sido excluidos de las lógicas formales de producción de ciudad (CLICHEvsky, 2009). En este sentido, la informalidad comprende, al decir de VARELA y CRAvino (2008), las múltiples formas de hábitat popular.

Asociada a su condición de "irregular" en el acceso al hábitat (HERZer ET AL., 2008), la ciudad informal muestra desventajas respecto de la ciudad formal, vinculadas con su ubicación en áreas no urbanizables/urbanizadas. Cabe resaltar, entre otras, la falta de acceso a bienes y servicios urbanos básicos (Clichevsky, 2009), precarias condiciones habitacionales, así como una mayor exposición a posibles situaciones de riesgo ambiental. Estos factores generan en la población mayor vulnerabilidad respecto de quienes habitan la ciudad "formal" (Píngaro LEFEVRE ET AL., 2016), que se acrecienta si se consideran otros factores sociales y económicos.

Desde un enfoque urbano, la vulnerabilidad se define como la posibilidad de toda o cierta parte de la población de un espacio determinado de ser afectada por riesgos o cambios en las múltiples dimensiones de la estructura urbana, que podrían significar condiciones de desventaja y fragilidad para los habitantes (Gómez ET AL., 2014; Romo ET AL., 2017). La vulnerabilidad es, en esta definición, un concepto multidimensional, contextual y subjetivo (Ruiz, 2019). Multidimensional, dado que reconoce que las problemáticas que afectan a ciertos sectores de la ciudad son variadas y pueden acrecentarse en la medida en que se combinen entre sí; contextual, porque no en todos los lugares las situaciones problemáticas son las mismas y subjetiva, dado que, como construcción conceptual, existen diversos enfoques para su abordaje y, por lo tanto, diversas formas metodológicas de aproximarse a ella. 
Si bien la vulnerabilidad resulta un aspecto clave para reconocer situaciones que requieren intervenciones urbanas en múltiples dimensiones, normalmente este aspecto no es tenido en cuenta en la atención de la informalidad (Píngaro Lefevre eT AL., 2016).

Consecuencia de una visión parcial sobre las problemáticas presentes en los asentamientos informales, las políticas urbanas destinadas a estos sectores se reducen generalmente a acciones focalizadas (HABITAT UN, 2015). Los criterios utilizados para su abordaje priorizan, en ese sentido, una perspectiva legal por sobre una perspectiva de derechos (LeFEBVRE, 2017) $y$, por ello, tienden a buscar soluciones fundamentalmente sobre indicadores de tenencia de la tierra y disponibilidad de servicios básicos (SMOLKA \& BiDERMAN, 2009). No contemplan, comúnmente, factores como recursos familiares, estructura de oportunidades de acceso al hábitat y capacidades institucionales existentes para su atención (Katzman, 1999; Busso, 2001). Por otra parte, las intervenciones tienden a realizarse exclusivamente desde la perspectiva estatal, dejando de lado valoraciones de otros actores involucrados, en particular de los habitantes. Prima por ello una visión sectorial por sobre la mirada territorial (Píngaro Lefevre, 2016), que deja así vacíos que reproducen la vulnerabilidad en estos espacios (Di VIRGILIo, 2015). Desde una perspectiva de derechos, se entiende que existen problemas derivados de la informalidad en torno a la exclusión socio-espacial que sufren los habitantes de áreas informales (HABITAT UN, 2015). El enfoque de vulnerabilidad urbana, incorporando una perspectiva multiactoral, aporta, en este sentido, importantes elementos para un análisis rico, consensuado y adecuado respecto de la identificación de estos problemas, y reviste gran importancia para futuros abordajes integrales de atención.

En su aspecto contextual, las problemáticas específicas que la vulnerabilidad urbana representa en las urbanizaciones informales varían de un lugar a otro, según las condiciones generales, los riesgos existentes y las capacidades de gobiernos y habitantes para hacerles frente (Romo ET AL., 2017). En el caso de Ushuaia, capital de la provincia de Tierra del Fuego AIAS, la informalidad surgió en la década del 70 vinculada con el acelerado crecimiento demográfico que produjo el proceso de industrialización del ex Territorio Nacional (MASTROSCELLo, 2008). La escasa oferta habitacional, las políticas urbano-habitacionales implementadas en los años posteriores y la creciente especulación inmobiliaria sobre el suelo y la vivienda condujeron a que el $54 \%$ del espacio urbano residencial producido hasta 2015 mostrara origen informal (FANK, 2019). Las causas y las formas que adoptó la informalidad no fueron las mismas en el tiempo transcurrido desde entonces, como tampoco las problemáticas 
asociadas a esta. Partiendo del reconocimiento de tipologías de informalidad ${ }^{1}$ (CLICHEvsKY, 2003; Di Virgilio, 2015; Cravino, 2013), se observan grandes diferencias entre las urbanizaciones informales de los años 80 y 90, con aquellas que tuvieron su origen a partir de 2000. Antiguos barrios informales localizados dentro de la trama urbana muestran características muy distintas que los nuevos asentamientos en la periferia de la ciudad consolidada, ocupando áreas de riesgo ambiental. La localización en la ciudad y el momento histórico de constitución de los asentamientos definieron diferentes grados y formas de vulnerabilidad. Las condiciones climáticas extremas y la fragilidad ambiental debidas a la ubicación de Ushuaia en el extremo sur del país constituyen un agravante del problema e intensifican la necesidad de estudios específicos en la zona. A pesar de ello, el conocimiento de la vulnerabilidad urbana no ha constituido un criterio para la definición de intervenciones y prioridades de atención de la informalidad, si bien existieron múltiples manifestaciones en la ciudad que reclamaban soluciones para el acceso al hábitat digno (MarTínez, 2017).

Por lo expuesto, el objetivo del presente trabajo es definir y comparar desde la visión de distintos actores, la vulnerabilidad urbana de los asentamientos informales de Ushuaia, considerando la integralidad de las problemáticas que afectan las condiciones de vida en estos espacios. Para ello, se determina el grado de vulnerabilidad urbana de dichos asentamientos, a través de la aplicación de un índice ${ }^{2}$ definido en forma conjunta con referentes barriales, actores de la academia y del Estado local, del cual se desprende la composición de la vulnerabilidad desde diferentes visiones. Los resultados de la aplicación del índice se analizan desde una perspectiva comparativa en dos niveles: la composición de la vulnerabilidad en los distintos asentamientos y las visiones de los diferentes actores, a través de sus valoraciones.

En el primer apartado se abordan los debates actuales en torno a la vulnerabilidad urbana y su medición. En el segundo, se describen los aspectos metodológicos de esta investigación referidos a la identificación de asentamientos informales y a la aplicación del Índice de Vulnerabilidad Urbana (IVU). El tercer apartado muestra los resultados, incluyendo una breve caracterización de la informalidad urbana en Ushuaia y la definición de la vulnerabilidad urbana en asentamientos informales, analizando su grado y composición desde la visión de distintos actores. El cuarto apartado refiere a la discusión de los resultados, retomando el enfoque teórico y los dos niveles de comparación propuestos. Finalmente se presentan las conclusiones.
1. Las tipologías en la informalidad varían según una serie de criterios. CLICHEVSKY (2003) reconoce tipologías en función del momento histórico de producción de los espacios informales, de las formas de organización bajo las cuales fueron gestados y de su localización en la ciudad. DI VIRGILIO (2015) distingue entre la informalidad producida sobre tierra vacante y sobre inmuebles. En el primer caso, diferencia villas, loteos y antiguos $y$ nuevos asentamientos, según características del tejido, precariedad del hábitat, formas y superficies de lotes, así como el emplazamiento en la ciudad, en áreas de intersticios urbanos o de periferia (CRAVINO, 2013).

2. Esto motivó la sanción de la Ley de Emergencia habitacional y Urbanoambiental en 2007 (Provincial $N .^{\circ} 746$ ), impulsada por organizaciones sociales (con prórrogas hasta 2019). 


\section{Múltiples enfoques para las múltiples vulnerabilidades urbanas}

Desde la disciplina urbanística, los estudios de vulnerabilidad tradicionalmente se enfocaron en dos cuestiones: áreas urbanas donde existen focos de pobreza y áreas que presentan problemáticas multidimensionales, resultado de la interacción de factores sociales, ambientales y económicos (Ruiz, 2019). En este segundo plano, se reconoce que no es el nivel de ingresos lo que caracteriza la vulnerabilidad urbana, sino la combinación de múltiples circunstancias que pueden conducir a la exclusión de ciertos grupos. Como plantea el enfoque de vulnerabilidad social (Busso, 2001), en la vulnerabilidad urbana tanto la estructura de oportunidades como los activos de los hogares y las capacidades institucionales pueden verse limitados. Factores como la localización y la asequibilidad generan distintas condiciones de oportunidad para los habitantes, y pueden producir desventajas. Estas serán mayores o menores en función de los recursos de las familias y de las instituciones que den respuesta a la problemática.

Existen variados trabajos que proponen abordajes analíticos para la medición de la vulnerabilidad urbana considerando su carácter multidimensional, la mayoría de ellos a través de la construcción de índices. Un índice es un instrumento de medición multidimensional y sintético, que posibilita hacer mediciones de forma comparativa, relacional y de manera agregada (SchuschNy \& Soто, 2009) en distintos contextos (PNUD, 2006). Entre los antecedentes se encuentra el trabajo de análisis de barrios vulnerables en España, el cual aplica un índice basado en indicadores seleccionados y ponderados por el Estado (GómEZ ET AL., 2014). VILLASmil (2013), por su parte, propone la medición de la vulnerabilidad urbana desde un enfoque ambiental y sistémico.

Si bien los enfoques tradicionales se centran en estudios fundamentalmente cuantitativos, Ruz (2019) incorpora a las tradicionales mediciones de vulnerabilidad urbana las percepciones de los sujetos-habitantes de la unidad de análisis de trabajo. Roмо ET AL. (2017) analizan en este sentido la vulnerabilidad socio-territorial en distritos chilenos a partir de un desarrollo metodológico, aplicando un enfoque multidimensional y multi-actoral. Los actores participan de la selección de variables, pero no en las discusiones sobre su relevancia. TECHO (2016), por su parte, aplica índices para la medición de la vulnerabilidad socio-territorial en asentamientos de algunas provincias argentinas. Si bien incorpora referentes barriales en la selección de variables, reconoce limitaciones al establecer grados 
de vulnerabilidad comparables únicamente entre asentamientos, no con el resto de la ciudad. Cabe destacar que el diseño y aplicación de estos enfoques responden a contextos muy distintos que el de Tierra del Fuego.

Si bien constituyen aportes importantes, estos trabajos no incorporan en la medición de la vulnerabilidad las diferentes perspectivas que tienen los actores involucrados en ella para determinar la relevancia de sus distintas dimensiones. La sociedad civil, el Estado en todos sus niveles, los actores del mercado (Pírez, 1995) y de la academia inciden con diferentes lógicas y movidos por distintos intereses en la producción del espacio urbano. La valoración sobre aquello que representa mayores o menores desventajas en la ciudad depende de lo que cada actor considere importante.

En el presente trabajo interesa incluir estas diferentes visiones no solo en la validación de los instrumentos de medición, sino en la definición del peso que tienen las múltiples dimensiones que componen la vulnerabilidad urbana. El enfoque multi-actoral permite otorgarle representatividad territorial al análisis propuesto (Roмо ET AL., 2017). Tanto la metodología como los resultados buscan explicitar las diferencias en las percepciones que los distintos actores tienen sobre la vulnerabilidad urbana y sobre sus puntos más relevantes, procediendo de esta forma a una construcción colectiva del conocimiento.

\section{Consideraciones metodológicas}

Para la identificación del grado de vulnerabilidad en asentamientos informales, se combinaron estrategias cuantitativas y cualitativas con estrategias de análisis espacial. La metodología utilizada consistió de dos etapas principales: 1) identificación y caracterización de asentamientos informales y 2) medición de la vulnerabilidad urbana en dichos asentamientos.

El área de estudio corresponde a la ciudad de Ushuaia. El grado de vulnerabilidad urbana de los asentamientos informales se definió en función de la totalidad del espacio urbano considerado. La unidad de análisis fue el radio censal, tomando como base el Censo Nacional de Población, Hogares y Viviendas (INDEC, 2010), lo cual permitió compatibilizar la información generada para áreas formales e informales y comparar los resultados en el tiempo y con otros contextos urbanos. 
3. Los trabajos sobre la definición del índice de vulnerabilidad tuvieron lugar en el marco de investigaciones de maestría $y$ doctorales que son parte de proyectos de investigación (PICT 2017-2020, GT CLACSO).

\section{Identificación y caracterización de asentamientos informales}

Se identificaron asentamientos informales como unidades susceptibles de intervención, determinando su localización geográfica y sus características socio-urbanas. Para su caracterización histórica, se utilizaron fuentes secundarias: registros municipales, ordenanzas, leyes y decretos municipales, informes del INDEC, de la Dirección de Estadística y Censos de la Provincia, y el trabajo propio sobre informalidad urbana (FANK, 2019) que caracteriza los asentamientos al año 2015.

Para la identificación de los asentamientos actuales se generó nueva información relativa a localización, forma y tejido. Se tuvieron en cuenta criterios de tenencia irregular y falta de acceso a dos servicios básicos: red de agua potable y desagües cloacales y/o red de energía eléctrica con medidor domiciliario. Se realizaron visitas a terreno y entrevistas con referentes barriales (tres) y con funcionarios municipales y provinciales: el director de Hábitat de Ushuaia y el director técnico del IPV (Instituto Provincial de Vivienda Tierra del Fuego). La información fue mapeada en SIG utilizando el software QGIS 3.2- BONN, sobre la base de imágenes disponibles de Google Earth.

\section{Medición de la vulnerabilidad urbana en Ushuaia}

El diseño metodológico para la medición de la vulnerabilidad urbana es producto de trabajos de investigación previos abocados a su desarrollo metodológico ${ }^{3}$. La propuesta analítica es una adaptación de la metodología propuesta por Scнuschnу у Sото (2009) para el "Diseño de indicadores compuestos de desarrollo sostenible”. Para su aplicación se siguieron los siguientes pasos: operativización del concepto de vulnerabilidad urbana; construcción, medición y normalización de indicadores; ponderación de indicadores y dimensiones; síntesis de todas las dimensiones, variables e indicadores analizados (construcción del IVU), aplicación del IVU y análisis de la vulnerabilidad.

La operativización del concepto de vulnerabilidad urbana se realizó, según el marco conceptual adoptado, partiendo del reconocimiento de tres componentes considerados en el enfoque de vulnerabilidad social (Katzman, 1999; Busso, 2001):

- Activos de las familias: refiere a los recursos materiales e inmateriales de los que disponen los sujetos y los hogares. Su capacidad de prevención y respuesta ante ciertos riesgos y amenazas (tanto naturales como antrópicas) incide en el nivel de vulnerabilidad. 
- Estructura de oportunidades que brinda el entorno: refiere a los posibilitantes y condicionantes que presenta el medio, tanto en términos de acceso urbano como en los aspectos ambientales. Pueden abarcar toda la ciudad o determinadas áreas particulares.

- Las instituciones que median esta relación: refiere a la existencia y capacidad de instituciones de incidir a través de ciertas acciones en la disminución de los riesgos y amenazas que presenta el medio y que pueden aumentar la vulnerabilidad urbana.

Para cada componente se identificaron dimensiones, variables e indicadores. La selección se realizó sobre la base de criterios de relevancia y posibilidad de construcción estadística. Para su validación, se efectuó una encuesta a 32 actores, que permitió arribar a un enfoque analítico consensuado. Los encuestados fueron seleccionados mediante la elaboración de un mapa de actores clave (MAC). En primer lugar, a partir de la realización de entrevistas a informantes con diferentes perspectivas y experiencias, se identificaron actores según criterios de relevancia y afinidad temática, y se clasificaron en grupos considerando su pertenencia sectorial (TAPELla, 2007). Posteriormente se analizaron las lógicas de acción y las relaciones predominantes de cada actor con el problema de estudio, basadas en el nivel de interés y en el nivel de poder e influencia. De esta forma, se obtuvo un MAC que presenta los siguientes actores clave, definidos en tres grupos: de la sociedad civil, de la academia y del Estado.

- Actores de la sociedad civil (siete): referentes de asentamientos informales de Ushuaia y ONG locales (barrios El Escondido, La Bolsita, Colombo, Dos Banderas, Andorra; Movimiento de Ocupantes e Inquilinos, Ingeniería sin fronteras).

- Actores de la academia (catorce): investigadores en temáticas vinculadas con el hábitat (INEC-Ecuador, UFFS-Brasil, CIPDH-UNESCO, IIGG, UNGS, CEVE-CONICET, UNTDF, INVIHAB, CIETES-CONICET).

- Actores del Gobierno Provincial y Municipal (once): funcionarios y profesionales (Provincia: Secretaría de Ordenamiento territorial, IPV. Municipio: Dirección General de Desarrollo Urbano, Dirección de Hábitat, Dirección de Información Territorial, Concejo Deliberante).

En las tablas 1, 2 y 3 se presentan las dimensiones, variables e indicadores finalmente considerados para la aplicación del IVU en Ushuaia, agrupados por componente de vulnerabilidad. Se incluyeron múltiples tipos de indicadores (Sснuscнnу \& Soто, 2009): sinópticos, basados en criterios contables, ciencias ambientales y de desempeño de políticas. 
Tabla 1

\section{Dimensiones, variables e indicadores del componente "Activos"}

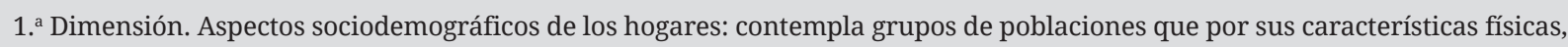
mentales, etárias, de nacionalidad y género, presentan mayores dificultades en el acceso al hábitat digno (HABITAT UN, 2015)

\begin{tabular}{l|l|l} 
Variable & Descripción & Indicadores \\
$\begin{array}{l}\text { 1.a. Grupos sociales de } \\
\text { riesgo }\end{array}$ & $\begin{array}{l}\text { Abarca grupos que por sus características etárias, físicas 0 } \\
\text { mentales ven disminuidas sus capacidades de adaptación } \\
\text { ante modificaciones en la estructura de oportunidades. }\end{array}$ & $\begin{array}{l}\text { \% población infantil (0 a 9 años) } \\
\% \text { adultos mayores (+ 65 años) } \\
\% \text { prevalencia de dificultades permanentes. }\end{array}$ \\
\hline $\begin{array}{l}\text { 1.b. Grupos vulnera- } \\
\text { bles beneficiaros de } \\
\text { políticas habitacionales }\end{array}$ & $\begin{array}{l}\text { Contempla grupos de nuevos migrantes, ya que estos presen- } \\
\text { tan normalmente valores de precariedad del hábitat (BAYONA } \\
\text { I CARRASCO, GAY, 2011). }\end{array}$ & \% población extranjera \\
\hline
\end{tabular}

2. ${ }^{a}$ Dimensión. Aspectos socio-económicos de los hogares: contempla las condiciones de empleo de los hogares

\begin{tabular}{l|l|l} 
Variable & Descripción & Indicadores \\
\hline 2.a. Inserción laboral & $\begin{array}{l}\text { Abarca grupos que no cuentan con un empleo formal, ya que } \\
\text { de él depende en gran medida el acceso al hábitat por la vía } \\
\text { formal (financiamiento). }\end{array}$ & $\begin{array}{l}\text { Tasa de empleo de los hogares } \\
\text { Tasa de desocupación de los hogares }\end{array}$ \\
\hline
\end{tabular}

3. ${ }^{a}$ Dimensión. Calidad de la vivienda entendida como valor de uso: contempla las condiciones mínimas que una vivienda debe poseer para ser considerada adecuada (HABITAT UN, 2015), en términos constructivos y en relación con el/los hogares que habitan en ella.

\begin{tabular}{|c|c|c|}
\hline Variable & Descripción & Indicadores \\
\hline $\begin{array}{l}\text { 3.a. Calidad construc- } \\
\text { tiva de la vivienda } \\
\text { 3.b. Adecuación del } \\
\text { hogar que reside en } \\
\text { la vivienda }\end{array}$ & $\begin{array}{l}\text { Contempla las características constructivas de las vivien- } \\
\text { das (estructurales y de funcionalidad). Se considera la } \\
\text { noción de vivienda deficitaria dada por el INDEC (2010). } \\
\text { Comprende la relación existente entre viviendas y hoga- } \\
\text { res que habitan las viviendas, tanto en términos de espa- } \\
\text { cio disponible como de la calidad del espacio en cuanto a } \\
\text { sus condiciones básicas. }\end{array}$ & $\begin{array}{l}\text { \% viviendas irrecuperables (incluye } \\
\text { las categorías: rancho, casilla, local no } \\
\text { construido para habitación, otros). } \\
\% \text { viviendas con hacinamiento crítico } \\
\text { por cuarto. } \\
\% \text { viviendas con allegamiento. } \\
\% \text { hogares con NBI. }\end{array}$ \\
\hline
\end{tabular}

4. ${ }^{a}$ Dimensión. Aspectos jurídicos vinculados con la tenencia de la tierra: situación legal en relación con el usufructo o propiedad de un inmueble, la cual está dada por el régimen de tenencia, que se clasifica como regular o irregular (INDEC, 2010)

\begin{tabular}{l|l|l}
\hline Variable & Descripción & Indicadores \\
\hline $\begin{array}{l}\text { 4.a. Condiciones de } \\
\text { tenencia }\end{array}$ & $\begin{array}{l}\text { Refiere a los hogares que no poseen un vínculo legal/for- } \\
\text { mal con el espacio residencial donde habitan. Se considera } \\
\text { la noción de tenencia irregular aportada por INDEC (2010) }\end{array}$ & $\begin{array}{l}\text { \% hogares con tenencia irregular (vi- } \\
\text { vienda en préstamo, hogares no propie- } \\
\text { tarios del terreno, otras modalidades). }\end{array}$ \\
\hline
\end{tabular}

Se excluyen en este trabajo aspectos relativos al máximo nivel educativo alcanzado por falta de Fuente: elaboración propia información disponible desagregada a nivel espacial. 
Vulnerabilidad urbana en asentamientos informales de Ushuaia.

Una aproximación analítico-comparativa desde la mirada de distintos actores

Tabla 2

Dimensiones, variables e indicadores del componente "Estructura de oportunidades"

5. a Dimensión. Asequibilidad: se entiende como la relación entre los ingresos y el costo que implica acceder a una propiedad (ONU, 2019).

\begin{tabular}{l|l|l} 
Variable & Descripción & Indicadores \\
5.a. Asequibilidad & $\begin{array}{l}\text { Contempla la posibilidad de acceso a suelo urbano y al } \\
\text { mercado de alquiler. Se considera asequible una vivienda } \\
\text { si el hogar destina menos del } 30 \% \text { de sus ingresos en gas- } \\
\text { tos asociados a ella (ONU, 2019). }\end{array}$ & $\begin{array}{l}\text { Asequibilidad en relación con el suelo } \\
\text { Asequibilidad en relación con el mer- } \\
\text { cado de alquileres }\end{array}$ \\
\hline
\end{tabular}

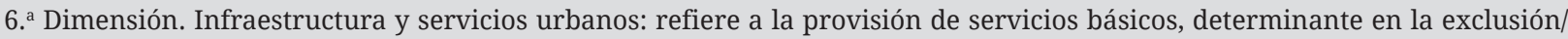
inclusión urbana

\begin{tabular}{|c|c|c|}
\hline Variable & Descripción & Indicadores \\
\hline 6.a. Accesibilidad & $\begin{array}{l}\text { Refiere a la posibilidad de tránsito tanto peatonal como ve- } \\
\text { hicular de todas las personas por todos los sectores dentro } \\
\text { de la ciudad (incluso de quienes posean limitaciones físi- } \\
\text { cas), y la presencia de transporte público. }\end{array}$ & $\begin{array}{l}\text { Accesibilidad vehicular } \\
\text { Accesibilidad para movilidad reducida } \\
\% \text { hogares sin acceso a transp. público }\end{array}$ \\
\hline $\begin{array}{l}\text { 6.b. Acceso a servicios } \\
\text { urbanos }\end{array}$ & $\begin{array}{l}\text { Refiere a la existencia dentro de la vivienda de servicios con- } \\
\text { siderados indispensables según ONU-Hábitat (2019), como } \\
\text { son provisión de agua potable, instalaciones sanitarias ade- } \\
\text { cuadas, energía para cocción, calefacción e iluminación, } \\
\text { conservación de alimentos y eliminación de residuos. }\end{array}$ & $\begin{array}{l}\text { \% hogares sin agua de red } \\
\% \text { hogares sin red de gas } \\
\% \text { hogares sin desagüe de red } \\
\% \text { hogares sin red eléctrica } \\
\% \text { de hogares sin s. de recolección de basura }\end{array}$ \\
\hline
\end{tabular}

7. a Dimensión. Equipamiento urbano: contempla las distancias de las viviendas a equipamientos urbanos básicos, como son centros de salud, de educación, comunitarios y espacios públicos.

\section{Variable}

7.a. Acceso a equipamientos públicos 7.b. Acceso a espacios públicos

\section{Descripción}

Refiere a la ubicación de las viviendas en relación con los equipamientos urbanos básicos. Una distancia transitable en un período corto resulta fundamental para asegurar el acceso democrático.

Refiere tanto a la cantidad de espacio público disponible como a su distribución en las áreas urbanas. Resulta fundamental para asegurar buenas condiciones de salud física y mental.

\section{Indicadores}

\% hogares a más de $700 \mathrm{~m}^{2}$ de escuelas primarias

$\%$ hogares a más de $1000 \mathrm{~m}^{2}$ de centros de salud

$\%$ hogares a más de $1500 \mathrm{~m}^{2}$ de centros comunitarios

$\%$ espacio público por habitante

$\%$ hogares sin acceso a espacio público a $300 \mathrm{~m}^{2}$

Sigue en página 92 
8. ${ }^{\text {a }}$ Dimensión. Condiciones ambientales: contempla la existencia de problemáticas y factores ambientales asociados a la localización de los emplazamientos, que inciden en las condiciones de habitabilidad.

\begin{tabular}{l|l|l} 
Variable & Descripción & Indicadores \\
$\begin{array}{l}\text { 8.a. Condición del } \\
\text { emplazamiento }\end{array}$ & $\begin{array}{l}\text { Refiere a las características de localización de las vivien- } \\
\text { das. Esta debe garantizar condiciones mínimas de salu- } \\
\text { bridad y también de inserción social. }\end{array}$ & $\begin{array}{l}\text { \% hogares en zonas sin capacidad de drenaje } \\
\% \text { hogares sobre rellenos de residuos urbanos }\end{array}$ \\
\hline $\begin{array}{l}\text { 8.b. Áreas expues- } \\
\text { tas a problemáti- } \\
\text { cas ambientales }\end{array}$ & $\begin{array}{l}\text { Refiere a viviendas ubicadas en áreas que por sus caracte- } \\
\text { rísticas físicas, pueden representar riesgos para el hábitat } \\
\text { humano. Estas características se seleccionaron especial- } \\
\text { mente para el caso de Ushuaia. }\end{array}$ & $\begin{array}{l}\% \text { hogares en laderas con pendiente mayor a 25 } \\
\% \text { hogares en relleno sobre humedales } \\
\% \text { hogares que reciben efluentes contaminantes }\end{array}$ \\
\hline $\begin{array}{l}\text { 8.c Factores } \\
\text { climáticos }\end{array}$ & $\begin{array}{l}\text { Contempla factores climáticos que en sus valores extre- } \\
\text { mos, pueden dificultar las condiciones de vida. }\end{array}$ & $\%$ hogares expuestos a acumulación de nieve \\
\hline
\end{tabular}

Tabla 3

Fuente: elaboración propia

\section{Dimensiones, variables e indicadores del componente "Capacidades institucionales"}

9. ${ }^{\text {a }}$ Dimensión. Capacidades municipales: refiere tanto a las capacidades técnicas como de gestión y a la disponibilidad de instrumentos de políticas públicas que tienen incidencia en la configuración territorial

\section{Variable Descripción}

9.a. Capacidades en relación con el hábitat accesible

\section{Contempla acciones impulsadas por el Estado (munici-} pal y provincial en este caso) que busquen garantizar el acceso al hábitat digno de toda la población. Se tuvieron en cuenta la existencia de programas de acceso a suelo y vivienda, así como de instrumentos de gestión urbana según la clasificación que propone Reese (2011).

9.b. Capacidades en relación con la atención de la informalidad Contempla acciones específicas impulsadas por los estados locales y provinciales para atención de la informalidad. Se contemplaron capacidades técnicas e instrumentos disponibles.

\section{Indicadores}

Programas de acceso a suelo y vivienda Instrumentos de financiamiento.

Instrumentos de planificación.

Instrumentos de promoción y desarrollo. Instrumentos de redistribución de costos y beneficios

Instrumentos de identificación de informalidad urbana

Estructura institucional para la atención de la informalidad

Programas específicos para la atención de la informalidad

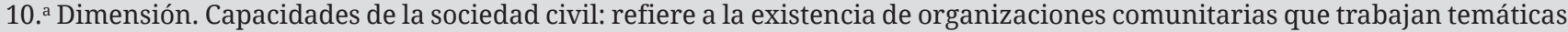
vinculadas con el acceso al hábitat

\begin{tabular}{l|ll} 
Variable & Descripción & Indicadores \\
$\begin{array}{l}\text { 10.a. Presencia de or- } \\
\text { ganizaciones sociales }\end{array}$ & $\begin{array}{l}\text { Refiere a la existencia de organizaciones sociales a nivel } \\
\text { urbano y barrial, supone una herramienta de los habitan- } \\
\text { tes para generar mejores condiciones de vida. }\end{array}$ & $\begin{array}{l}\text { Existencia de organizaciones a escala } \\
\text { local. } \\
\text { Existencia de organizaciones a escala } \\
\text { barrial. }\end{array}$ \\
\hline
\end{tabular}

Fuente: elaboración propia 
La construcción de los indicadores requirió distintas estrategias para su definición, según las fuentes, tipos de datos utilizados y la unidad de análisis afectada. De acuerdo con estos criterios, se determinaron los siguientes grupos de indicadores:

- Grupo 1: basados en información censal de población, hogares y viviendas por radio censal (unidad de análisis). Se espacializaron datos provenientes del CNPHV (Censo Nacional de Población, Hogares y Vivienda), mediante programa QGIS 3.4.8. Contiene indicadores de las variables: 1.a; 1.b; 2.a; 3.a; 3.b; 4.a; 6.b.

- Grupo 2: basados en el análisis espacial por radio censal (unidad de análisis). Los datos necesarios para su producción no se encuentran incluidos en el censo, ya que refieren a cuestiones específicas de cada lugar. Por ello se construyeron bases de datos espaciales en QGIS 3.4.8 para cada indicador, utilizando fuentes de datos oficiales provenientes de organismos públicos. Contiene indicadores de las variables: 6.a; 7.a; 7.b; 8.a y 8.b.

- Grupo 3: construidos considerando la ciudad como unidad de análisis (se les asignó el mismo valor a todos los radios censales). Dado que afectan a la ciudad de manera homogénea, no se produjeron datos desagregados espacialmente. Se utilizaron fuentes de datos oficiales provenientes de organismos públicos y datos de precio de suelo y alquiler de inmobiliarias locales (para asequibilidad). Contiene indicadores de las variables: 5.a; 8.c; 9.a; 9.b; 10.a.

Posteriormente se realizó la medición de los indicadores en todos los radios censales de Ushuaia. En primer lugar, se espacializaron los valores numéricos de afectación para cada radio censal. Luego se transformaron en valores de vulnerabilidad, mediante la definición de cinco rangos: no vulnerable ( $0 \%$ de afectación); vulnerabilidad baja ( $0 \%-24,9$ $\%$ de afectación); vulnerabilidad media-baja ( 25 \% - 49,9 \% de afectación); vulnerabilidad media-alta ( $50 \%-74,9 \%$ de afectación) y vulnerabilidad alta (75 \% y más). Los criterios operativos de corte para los indicadores pertenecientes a los grupos 1 y 2 fueron establecidos según proporción afectada de radio censal, en función de los valores máximos y mínimos encontrados en el conjunto de valores. En el caso de los indicadores pertenecientes al grupo 3, los cortes fueron establecidos según criterios cualitativos ${ }^{4}$.

La normalización consistió en la estandarización de los resultados de la medición de cada indicador por radio censal. Este paso fue necesario dado que los indicadores contienen diferentes unidades de medidas y diferentes rangos de valoración. Para ello, se transformaron los valores en unidades adimensionales en una escala entre 0 y 1 utilizando el método de máximos y mínimos (PNUD, 2006). Esto permitió establecer valores
4. La desviación estándar fue descartada como criterio de corte, ya que esta permitía ver únicamente valores extremos de desviación (aquellos que se encuentran por fuera de la desviación media), pero no resultaba útil para el establecimiento de gradientes. 
comparables, donde 0 equivale al valor mínimo de vulnerabilidad y 1 al valor máximo, considerando en cada caso la dirección positiva o negativa del indicador.

La ponderación de los indicadores y dimensiones de vulnerabilidad permitió establecer la relevancia del valor de cada elemento en la composición final del IVU. El criterio de ponderación fue el consenso respecto de la valoración, establecido al interior de los tres grupos de actores previamente definidos. Para ello se aplicó el Método Delphi, el cual "consiste en una técnica de obtención de información, basada en la consulta a expertos de un área, con el fin de obtener la opinión de consenso más fiable del grupo consultado" (REGUANT-ÁlVAREZ \& Torrado-Fonseca, 2016, p. 88). La aplicación se realizó siguiendo las fases contempladas en el método. Sobre la base de las dimensiones, variables e indicadores definidos (primera fase), se realizó un cuestionario a los 32 actores antes nombrados, separados por grupo, definiendo así tres sistemas de ponderación (segunda fase). En el cuestionario se requirió que definieran la relevancia de cada indicador y dimensión mediante un valor numérico discreto, asignándoles mayor o menor importancia según nivel de vulnerabilidad. Los resultados se volcaron en matrices de indicadores y niveles de importancia (se obtuvieron once matrices, una para cada dimensión y una con el total de dimensiones). Las respuestas se sistematizaron según tipo de actor para cada dimensión y para cada indicador. Posteriormente se aplicó un análisis estadístico simple de las respuestas por grupo de actor, buscando determinar la representatividad de la incidencia de cada indicador. Se definió un coeficiente de variación entre respuestas del mismo tipo, y en los casos donde la media no fue representativa del grupo encuestado, se realizó una nueva ronda de preguntas a los encuestados correspondientes (tercera fase). Una vez definidos los valores medios de cada respuesta consensuada, se procedió a la aplicación de una fórmula, que permitió establecer valores de ponderación para cada indicador y cada dimensión (cuarta fase). La fórmula consiste en establecer un coeficiente K, según la siguiente expresión:

$$
\mathrm{k}=\frac{1}{\left(\frac{1}{\mathrm{i}_{1.1}}+\frac{1}{\mathrm{i}_{1.2}}+\frac{1}{\mathrm{i}_{1.3}}+\cdots+\frac{1}{\mathrm{i}_{\mathrm{n}}}\right)} \quad \begin{aligned}
& \mathrm{i}_{1.1}: \text { Valor medio del indicador 1.1; } \\
& \mathrm{i}_{1 . \mathrm{n}: \text { Valor medio del indicador 1.n }}
\end{aligned}
$$

Los factores de

ponderación se calcularon: $\left(\mathrm{fpi}_{1}\right)=\frac{\mathrm{k}}{\mathrm{i}_{1.1}} ;\left(\mathrm{fpi}_{2}\right)=\frac{\mathrm{k}}{\mathrm{i}_{1.2}} \ldots \ldots \ldots ;\left(\mathrm{fpi}_{\mathrm{n}}\right)=\frac{\mathrm{k}}{\mathrm{i}_{1 . n}}$ fpi $_{i}:$ Valor del factor de ponderación del indicador $i_{i}$ 
De esta forma se obtuvieron los valores finales de los factores de ponderación de cada indicador dentro de su dimensión correspondiente para los tres grupos de actores encuestados. La fórmula se aplicó de igual manera para la ponderación de las distintas dimensiones.

El IVU constituye la síntesis de todas las dimensiones, variables e indicadores analizados. Se obtuvo en primer lugar un "subíndice" por cada dimensión, como la sumatoria del producto de cada indicador por su factor de ponderación. El índice final es la sumatoria de los valores de los subíndices de todas las dimensiones ponderadas.

\section{$I V U=\left(S D_{1}^{*} f p d_{1}\right)+\ldots . .+\left(S D_{i}^{*} f p d_{i}\right)$ \\ IVU : Índice de Vulnerabilidad Urbana \\ $S D_{i}$ : Subíndice correspondiente a la dimensión $i$ \\ $\mathrm{fpd}_{i}$ : Factor de ponderación correspondiente a dimensión $i$}

De su aplicación en todos los radios censales de Ushuaia se obtuvieron los resultados, que consistieron en primera medida en un valor teórico donde el rango entre 0 y 1 refleja la mejor y peor situación, respectivamente, según los niveles de vulnerabilidad ya nombrados. En segunda medida, se espacializaron los valores del IVU por radio censal mediante la utilización del software QGIS 3.2- BONN. Se obtuvieron tres mapas de vulnerabilidad urbana, a los que se superpusieron los asentamientos informales identificados. Se definió el grado de vulnerabilidad que posee cada asentamiento informal según los distintos grupos de actores.

Finalmente se procedió al análisis de la composición de la vulnerabilidad urbana en los sectores que mostraron mayor grado. Se tomaron valores medios de los subíndices correspondientes a cada dimensión ponderados según los distintos actores, y se transformaron en porcentajes de nivel de vulnerabilidad. Los resultados se volcaron en gráficos de radar.

\section{Resultados}

Los resultados muestran en primer lugar una breve caracterización histórica de la informalidad urbana en Ushuaia y el estado de situación de los asentamientos informales actualizado a 2020. Posteriormente se define la vulnerabilidad urbana mediante la aplicación del IVU en los distintos radios censales y se realiza un análisis comparativo de la composición de la vulnerabilidad en los asentamientos informales más afectados. 


\section{Informalidad urbana en Ushuaia. Producción histórica y reciente}

La informalidad urbana en Ushuaia está intrínsecamente asociada al proceso de crecimiento de la ciudad, desde el comienzo de la promoción industrial en la provincia. Ushuaia es la ciudad más austral del mundo; está ubicada al pie de la cordillera de los Andes en el externo sur de la isla Grande de Tierra del Fuego. El relativo aislamiento geográfico y el clima subantártico, caracterizado por largos y crudos inviernos, ralentizaron su proceso de poblamiento. A partir de 1972, Ushuaia comenzó a crecer aceleradamente a causa del impulso a la actividad industrial por parte del Gobierno Nacional, mediante la sanción de un régimen de promoción especial para Tierra del Fuego (Ley N. ${ }^{\circ}$ 19640). La población se quintuplicó entre 1970 y 1991: pasó de 5677 a 29.505 habitantes, continuó creciendo sostenidamente por encima de la media nacional y alcanzó los 76.945 habitantes en 2015 (MARTínEz, 2017). Frente a la ausencia de planificación y políticas urbano-habitacionales que brindaran respuestas a la nueva población, la informalidad se consolidó como forma de ocupación característica del espacio durante la década del 80, representando para 1991 el 31 \% del espacio residencial existente (FANK, 2019), tal como se muestra en la figura 1. La provisión de servicios y la regularización dominial expost sobre lotes que de manera individual y espontánea se construían sobre tierras fiscales fueron una práctica habitual en la constitución de los barrios de aquella época.

Durante los años 90, la mayoría de las acciones desde el gobierno municipal giraron en torno a la regularización de barrios de décadas anteriores. La informalidad continuó creciendo ante las escasas políticas de acceso al suelo existentes. Dado que el Canal Beagle al sur, los cordones montañosos hacia el norte y el este, el parque nacional y las tierras privadas al oeste constituían barreras para el crecimiento por expansión, las urbanizaciones informales comenzaron a avanzar sobre tierras fiscales no aptas para urbanización, en los bordes de la trama urbana consolidada. Se extendieron hacia el norte sobre laderas, por encima de la cota definida como máxima urbanizable, y hacia el este en el llamado valle de Andorra, un espacio planificado originalmente para uso productivo primario. De las 543 ha de expansión residencial entre 1991 y 2003, los asentamientos informales representaron el $28,7 \%$ y mostraron mayores complicaciones que en la década anterior, tanto por las condiciones geográficas de los emplazamientos como por las políticas urbanas de aquel momento. Muchas de estas situaciones continúan siendo informales al presente.

A partir del año 2003, con un nuevo impulso a la industria, las nuevas migraciones asociadas tanto a dicha actividad como al turismo y desarticuladas nuevamente de políticas de acceso 
al suelo y a la vivienda condujeron al crecimiento de la informalidad. Frente a la "falta" de espacio disponible, los asentamientos avanzaron sobre laderas de montaña, sobre turbales y hacia el interior del valle de Andorra. Esto provocó la profundización de las problemáticas existentes y la aparición de nuevas situaciones de riesgo asociadas a localizaciones no aptas para urbanización (FANK, 2019). Los asentamientos crecieron considerablemente entre 2010 y 2015, a causa de la especulación inmobiliaria y la falta de vivienda asequible. La lejanía respecto de la ciudad consolidada y las dificultosas condiciones de accesibilidad comenzaron a definir fuertes condiciones de exclusión socio-espacial en estos sitios. De las 615 ha de expansión de uso residencial en la ciudad entre 2003 y 2015, la expansión informal representó el 76 \%.

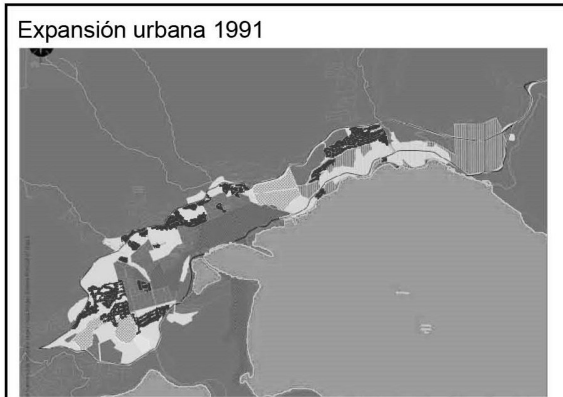

Formal: $325,5 \mathrm{Ha}$.

Expansión urbana 2010

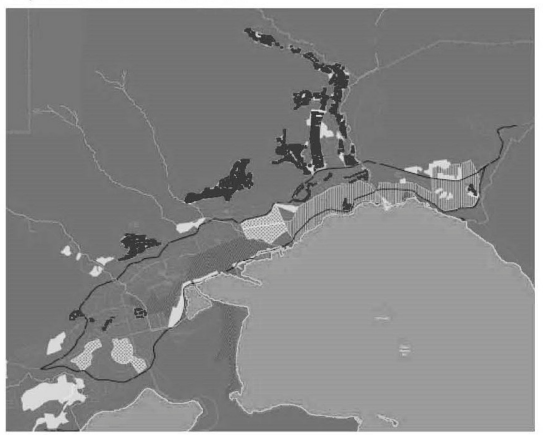

Formal: $58,57 \mathrm{Ha}$.

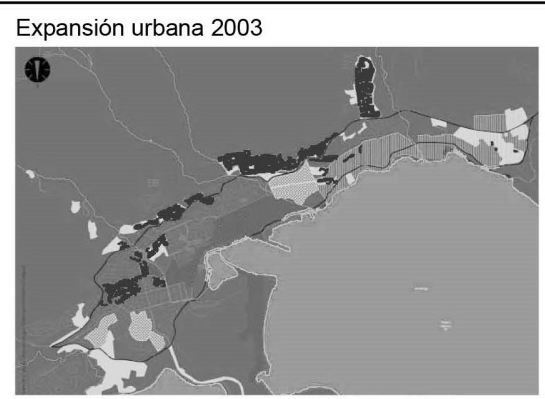

Formal: $387,3 \mathrm{Ha}$

Expansión urbana 2015

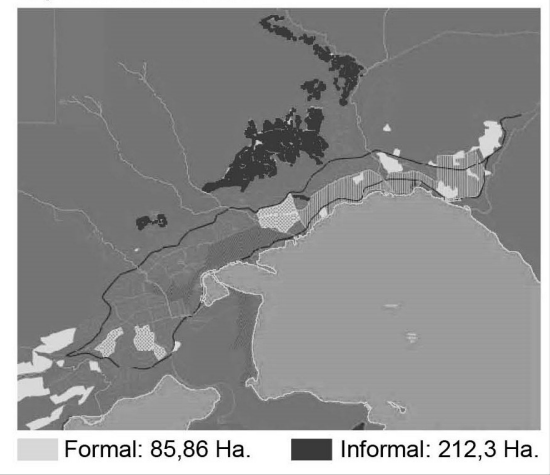

Figura 1.

Expansión urbana formal e informal en Ushuaia, 1972-

2015. Fuente:

adaptación FANK, 2019 
Con respecto a las características que la informalidad asumió a través del proceso de su constitución, se observa que, si bien durante los años 70 y 80 no existieron diferencias marcadas entre los espacios formales e informales, la disponibilidad de tierras fiscales exclusivamente en áreas periféricas condujo a que en las décadas posteriores (en particular desde 2003) se produjeran claras diferenciaciones entre la ciudad formal y la informal.

Figura 2. Configuración urbana formal e informal en Ushuaia

Fuente: elaboración propia

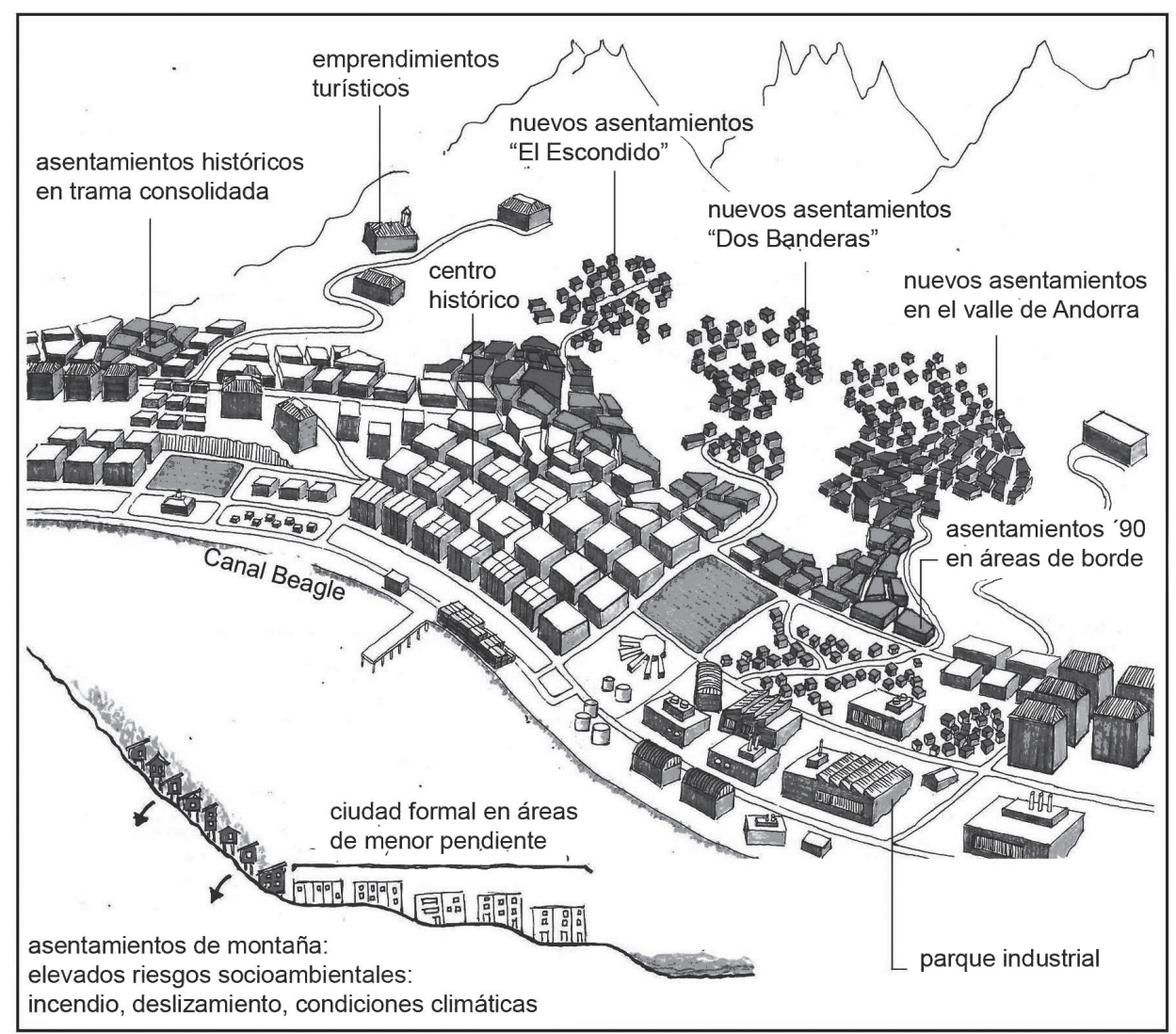


En la actualidad se observan asentamientos históricos ubicados en el interior de la trama urbana consolidada y asentamientos posteriores a 2003 fuera de la mancha urbana. Puede señalarse, asimismo, otra diferencia relacionada con el origen individual de la informalidad en los 80 y su carácter disperso en el territorio, mientras que los asentamientos posteriores a 2003 fueron producidos de manera colectiva, en áreas periféricas y de difícil accesibilidad. En la actualidad existen fundamentalmente tres sectores donde se concentran los nuevos asentamientos: hacia el norte, sobre la ladera de montaña en el sector conocido como "El Escondido", hacia el nordeste en la ladera del cerro Dos Banderas y en la zona del valle de Andorra. Algunas de las áreas en laderas presentan múltiples riesgos ambientales, a la vez que muestran condiciones de exclusión tanto física como social respecto del resto de la ciudad (figura 2).

Respecto de los asentamientos actuales, la figura 3 muestra la existencia de diecisiete asentamientos informales en Ushuaia: tres en el sector denominado "El Escondido"; cuatro

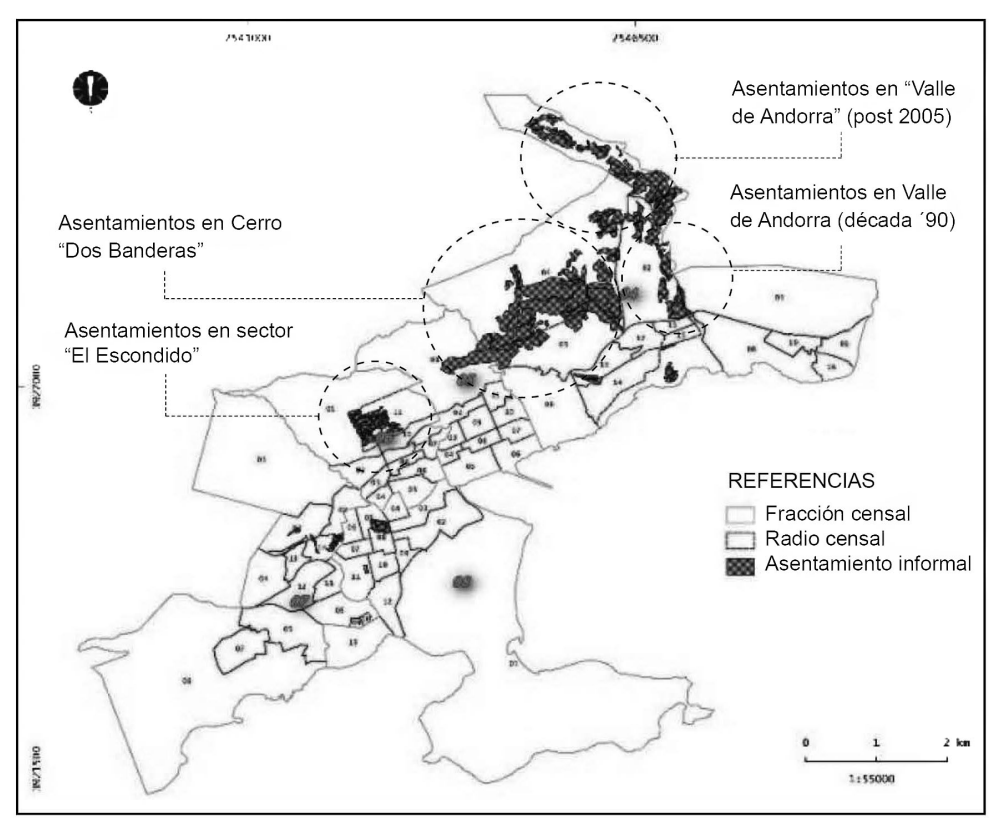

Figura 3.

Asentamientos informales en Ushuaia sobre radios censales, 2020

Fuente: elaboración propia. Elaboración cartográfica: Comes, 2020 
en el sector Dos Banderas y ocho en el valle de Andorra. Según un censo realizado en el año 2013, 684 familias habitaban en El Escondido, población estimada de 2314 personas, y 339 familias en el valle de Andorra, equivalente a 876 personas (Res. UEP N. ${ }^{\circ} 349 / 2013$ ). El Municipio de Ushuaia estima que la población creció un 50 \% al año 2020. Existen algunos asentamientos dentro del tejido urbano consolidado (Colombo, La Bolsita, 2 de Abril).

\section{Vulnerabilidad urbana en Ushuaia}

Los resultados de la aplicación del IVU en Ushuaia, según la valoración de la sociedad civil, la academia y el Estado (figuras 4, 5, y 6) muestran que el mayor grado de vulnerabilidad urbana en la ciudad es media-alta y corresponde a radios censales ocupados por asentamientos informales en los sectores El Escondido, Dos Banderas y valle de Andorra, ubicados en áreas de periferia urbana. Los sectores que muestran menor vulnerabilidad son los radios censales de la zona céntrica y al oeste, en un área residencial de alto nivel económico. El resto de la ciudad muestra un nivel de vulnerabilidad media-baja.

Se observa que para la sociedad civil, los asentamientos más vulnerables son los constituidos a partir de 2005 (Escondido, Dos Banderas y el sector nuevo de Andorra). Para la academia y el Estado, el sector de Andorra constituido en los 90 resulta asimismo de vulnerabilidad media-alta, aunque para los tres grupos (tabla 4) los asentamientos con mayor vulnerabilidad son los nuevos, localizados en la ladera de la montaña (El Escondido y Dos Banderas).

\section{Tabla 4}

Grado de vulnerabilidad de asentamientos informales en Ushuaia según radio censal, zona y tipo de actor

\begin{tabular}{l|lc|c|c}
\multirow{2}{*}{ Radio } & Zona & \multicolumn{3}{c}{ IVU } \\
\cline { 2 - 5 } & & S. Civil & Academia & Estado \\
\hline $4-4$ & Dos Banderas & 0,66 & 0,70 & 0,68 \\
\hline $6-12$ & El Escondido & 0,68 & 0,69 & 0,66 \\
\hline $6-11$ & El Escondido & 0,59 & 0,6 & 0,57 \\
\hline $4-3$ & Andorra post 2005 & 0,52 & 0,57 & 0,57 \\
\hline $4-2$ & Andorra (años 90) & 0,49 & 0,52 & 0,51 \\
\hline
\end{tabular}

Fuente: elaboración propia 
Vulnerabilidad urbana en asentamientos informales de Ushuaia.

Una aproximación analítico-comparativa desde la mirada de distintos actores

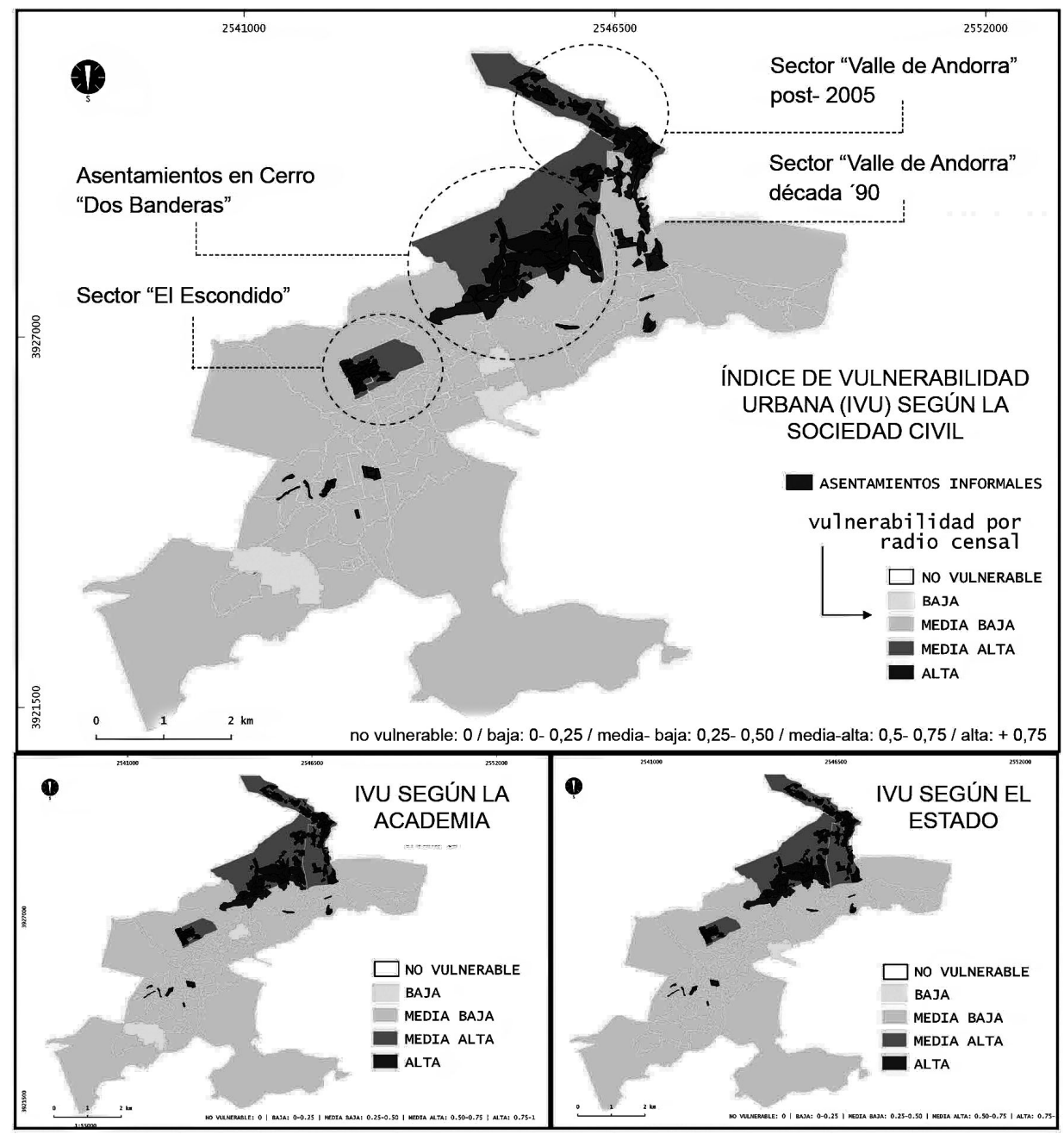

Figuras 4, 5, 6 .

Vulnerabilidad urbana en Ushuaia, según ponderación sociedad civil, academia y Estado

Fuente: elaboración propia

Elaboración cartográfica:

COMES, 2020 
Si bien en los sectores de asentamientos informales el nivel de vulnerabilidad urbana media-alta es el mismo, las dimensiones más acuciantes varían en cada caso tanto por sus condiciones particulares como por el tipo de actor que realizó la valoración. Se analiza a continuación la composición de la vulnerabilidad para los dos sectores más afectados.

\section{Composición de la vulnerabilidad urbana en asentamientos informales de los sectores El Escondido y Dos Banderas}

El peso que tienen las distintas dimensiones de la vulnerabilidad en los asentamientos del sector El Escondido difiere según la visión de los distintos actores. La figura 7 muestra la composición de la vulnerabilidad urbana con base en el cálculo del IVU, según las valoraciones de la sociedad civil, la academia y el Estado.

Para la sociedad civil, las condiciones de tenencia constituyen la dimensión principal de vulnerabilidad, seguidas por la calidad de la vivienda y luego por las condiciones económicas.

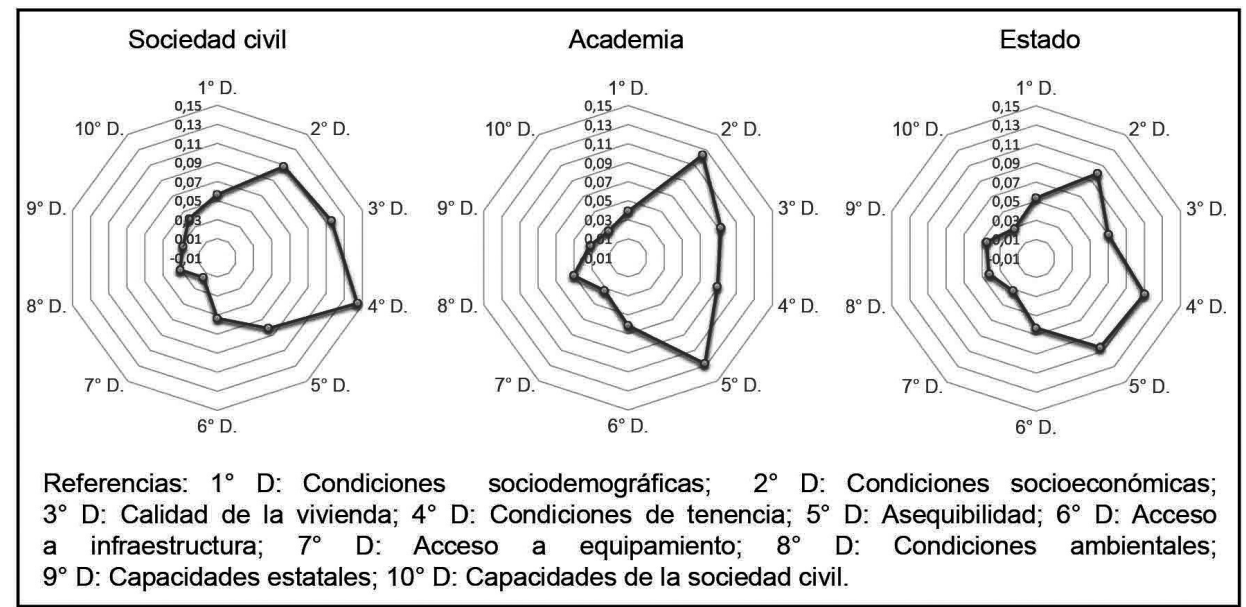

Figura 7. Composición de la vulnerabilidad urbana en asentamientos sector El Escondido Fuente: elaboración propia 
En el caso de la academia, las condiciones de asequibilidad representan el principal factor de vulnerabilidad, seguidas por las condiciones socio-económicas y por la calidad de la vivienda. Para este actor las condiciones de tenencia representan un factor menos importante. El Estado valora de manera similar tenencia y asequibilidad como factores fundamentales de vulnerabilidad, seguidas de condiciones socioeconómicas. A diferencia de los otros actores, le otorga menor peso a la calidad de la vivienda. El acceso a infraestructura es un factor de importancia media para todos los actores, aunque mayor para la academia y el Estado. Para ellos, las cuestiones ambientales también muestran mayor relevancia que para la sociedad civil. Las capacidades estatales constituyen un factor más relevante para el Estado que para los otros actores, aunque la academia le otorga cierta importancia. Las condiciones sociodemográficas, el acceso a equipamientos públicos y las capacidades de la sociedad civil no constituyen factores relevantes de vulnerabilidad para ninguno de los actores.

En el caso de los asentamientos del sector Dos Banderas, también es posible observar diferencias en la composición de la vulnerabilidad según la valoración de los distintos actores, como muestra la figura 8.

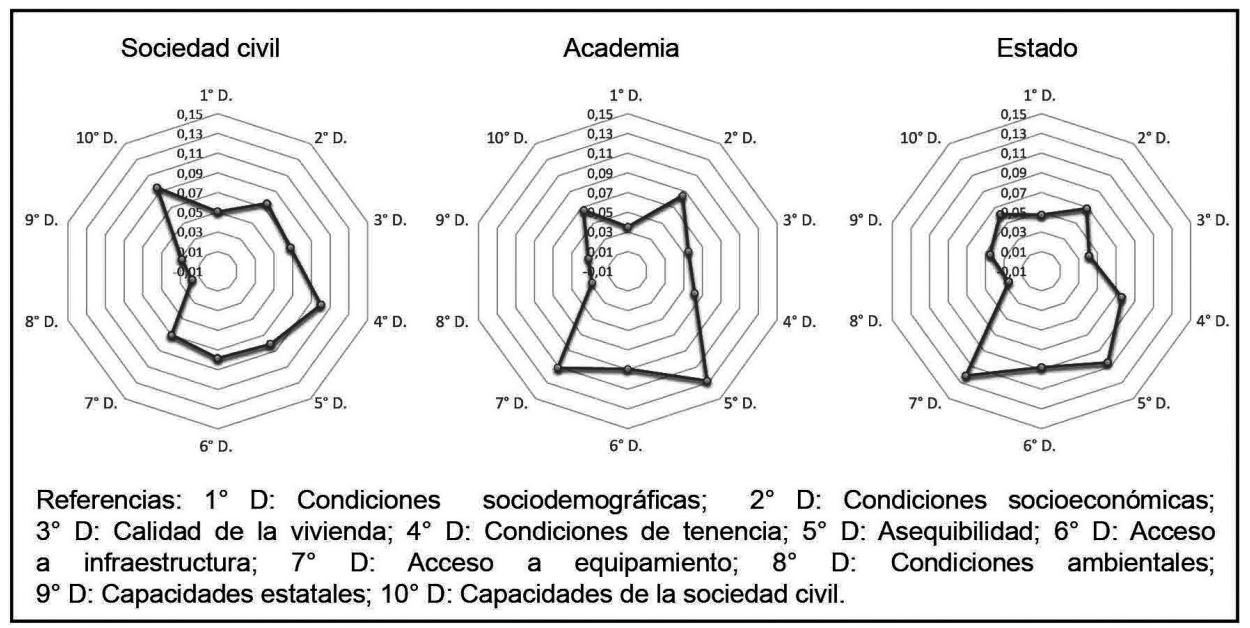

Figura 8. Composición de la vulnerabilidad urbana en asentamientos del sector Dos Banderas Fuente: elaboración propia 
5. Según el relevamiento realizado para el presente trabajo en febrero de 2020, tanto en la asequibilidad al suelo como en relación con el mercado de alquiler,

la ciudad muestra valores inaccesibles para la población que ronda el Salario Mínimo Vital y Móvil (SMVM).
Mientras que para la sociedad civil las condiciones de tenencia y las capacidades de la sociedad civil son las principales dimensiones de vulnerabilidad urbana, la asequibilidad y la falta de equipamientos públicos resultan las más relevantes para la academia. El Estado coindice con la visión de la academia, pero nuevamente le otorga más peso a la tenencia. La infraestructura implica una dimensión más importante de vulnerabilidad en este sector que en El Escondido, para los tres grupos de actores. Todos coinciden en que las condiciones socioeconómicas influyen menos en la vulnerabilidad urbana de los asentamientos de este sector, aunque estas tienen mayor peso para la academia. La calidad de la vivienda es un factor menos relevante de vulnerabilidad en este sector, aunque más valorado por la sociedad civil. La disponibilidad de equipamientos públicos representa una gran carencia para todos los actores, al igual que las capacidades de la sociedad civil. El lugar de menor importancia para los tres lo ocupan las condiciones ambientales. Las capacidades estatales son nuevamente más valoradas por el Estado que por los otros actores.

\section{Discusión}

Los resultados muestran que la vulnerabilidad urbana es mayor en asentamientos informales que en el resto de la ciudad, según la valoración de los tres grupos de actores. El mayor nivel de vulnerabilidad urbana es media-alta. Los mayores valores corresponden a nuevos asentamientos localizados fuera de la trama consolidada, lo que dificulta su integración urbana.

Se encuentran importantes diferencias en la composición de la vulnerabilidad en cada sector, tanto en los resultados que se desprenden de las mediciones por dimensión como entre las dimensiones consideradas más y menos relevantes según cada actor. Respecto de la comparación entre sectores, se observa que tanto en El Escondido como en el Dos Banderas tienen gran relevancia dentro de la vulnerabilidad las condiciones de asequibilidad ${ }^{5} \mathrm{y}$ también las de tenencia. Las condiciones socioeconómicas, la calidad de la vivienda y las condiciones ambientales son mayores factores de vulnerabilidad en los asentamientos de El Escondido que en el sector Dos Banderas. En este último, la falta de acceso a equipamientos públicos, el acceso a infraestructura y las capacidades de la sociedad civil son factores muy influyentes en la composición de la vulnerabilidad, aunque no lo son en el primer sector. Estas diferencias podrían explicarse por las condiciones geográficas y la localización en cada caso: mientras que El Escondido posee menores dimensiones, la pendiente del terreno mayor a $25^{\circ}$ dificulta 
el emplazamiento. En el caso del sector Dos Banderas, la gran extensión y baja densidad del asentamiento genera mejores condiciones para el emplazamiento, pero menor accesibilidad a la infraestructura urbana. Estos perfiles delimitan diferentes problemáticas en torno a la vulnerabilidad, así como requieren diferentes abordajes desde la política pública.

Respecto de la valoración de los actores, se observa que tenencia y servicios, indicadores típicos de la medición de informalidad, no representan necesariamente las principales problemáticas en los asentamientos para todos los actores. Para la academia, la tenencia no estuvo en ningún caso entre los factores principales de vulnerabilidad. El Estado, por su parte, fue el que más valor le otorgó a las capacidades estatales, y la sociedad civil la que más valoró las capacidades de la sociedad civil, aunque no ponderó como importantes las condiciones ambientales. La academia mantuvo como eje principal de vulnerabilidad a la asequibilidad. Esto demuestra la diferencia de visiones sobre vulnerabilidad urbana de los distintos actores.

Retomando el enfoque teórico, en la tabla 5 se observa la incidencia de los tres componentes de la vulnerabilidad urbana (activos, estructura de oportunidades y capacidades institucionales) en los sectores de asentamientos informales. El Escondido fue el que más vulnerabilidad respecto de los activos mostró, mientras que el valle de Andorra presentó la mayor incidencia de la estructura de oportunidades y las capacidades institucionales. Respecto de la comparación entre actores, los activos de las familias constituyeron el principal componente de vulnerabilidad urbana en los asentamientos para la sociedad civil. Esto es muy diferente para la academia y el Estado, que únicamente en "El Escondido" acuerdan con esta visión, mientras que en el "Dos Banderas" valoran como el componente principal de vulnerabilidad a la estructura de oportunidades que brinda el entorno. Resulta fundamental el lugar protagónico que adquiere la estructura de oportunidades en el abordaje de la informalidad, dado que corre el eje de los sujetos al medio como potenciador o limitante de las desventajas de vida en estos espacios. Las capacidades institucionales han mostrado ser un componente más importante para la sociedad civil y el Estado que para la academia.

La perspectiva multidimensional permite complejizar la mirada sobre las causas que inciden en la vulnerabilidad de los asentamientos. El abordaje multi-actoral deja entrever que las valoraciones sobre datos cuantitativos también son relativas, y por ello resulta interesante incorporar diferentes visiones en el diseño de políticas adecuadas de atención a la informalidad. 
Tabla 5

Composición de la vulnerabilidad urbana en componentes para los distintos actores

\begin{tabular}{lcc|ccc|c|c|c|c}
\hline \multirow{2}{*}{ Sector } & \multicolumn{3}{c}{ Activos (\%) } & \multicolumn{2}{c}{$\begin{array}{c}\text { Estructura de } \\
\text { oportunidades (\%) }\end{array}$} & \multicolumn{3}{c}{$\begin{array}{c}\text { Capacidades } \\
\text { institucionales (\%) }\end{array}$} \\
\cline { 2 - 10 } & S.C. & Academ. Estado & S.C. & Academ. Estado & S.C & Academ. & Estado \\
\hline El Escondido & 62 & 50,4 & 51,4 & 28 & 41,2 & 37,2 & 10 & 8,4 & 11,4 \\
\hline Valle Andorra & 44,2 & 34,2 & 34,4 & 37,2 & 51,5 & 50 & 18,6 & 14,3 & 15,7 \\
\hline
\end{tabular}

Fuente: elaboración propia

\section{Conclusiones}

La aplicación del IVU permitió conocer, desde diferentes perspectivas, el grado de vulnerabilidad de los asentamientos informales en Ushuaia y también su composición, es decir, los diferentes factores que inciden en la vulnerabilidad en cada uno de ellos.

El enfoque multidimensional aplicado posibilitó generar una comprensión integral de la problemática, visibilizando los factores y situaciones que deberían atenderse con mayor urgencia. Esto aporta un criterio para priorizar la atención de los casos que presentan mayor vulnerabilidad, y generar intervenciones pertinentes para cada situación de informalidad, considerando no solo su resolución en términos de acceso al suelo y a servicios, sino también de acceso a la ciudad. La metodología utilizada demostró que tanto el grado como la composición de la vulnerabilidad varían según el contexto y la visión del actor que la esté considerando, lo que refuerza la importancia de un análisis del fenómeno construido entre diferentes actores involucrados en la problemática.

El enfoque de vulnerabilidad urbana utilizado constituye un insumo factible de ser replicable en otros contextos que busquen promover acciones superadoras de las que actualmente se aplican en los asentamientos informales, a los fines de revertir las desventajas que históricamente han afectado estos espacios. Los avances presentados sirven de base para la formulación de políticas que busquen disminuir los niveles de vulnerabilidad urbana en asentamientos informales. 


\section{Referencias}

ABRAMO, P. (2012). La ciudad com-fusa: mercado y producción de la estructura urbana en las grandes metrópolis latinoamericanas. EURE (Santiago), 38(114), pp. 35-69.

BAYONA I CARRASCO, Jordi \& GAY Antonio (2011). Concentración, segregación y movilidad residencial de los extranjeros en Barcelona. En Documents d' Anàlisi Geogràfica, 57, 3. Pop 381-412. https://www.raco.cat/index.php/ DocumentsAnalisi/article/download/248435/332559

BUSSO, G. (2001). Vulnerabilidad social: nociones e implicancias de políticas para Latinoamérica a inicios del siglo XXI. Seminario internacional: Las diferentes expresiones de la vulnerabilidad social en América Latina y el Caribe. CEPAL-CELADE. Santiago de Chile, junio de 2001.

CLICHEVSKY, N. (2003). Cambios en el espacio metropolitano. En Catenazzi A, y Lombardo J.D. (Eds.), La cuestión urbana en los noventa en la Región Metropolitana de Buenos Aires. Universidad Nacional de General Sarmiento.

CLICHEVSKY, N. (2009). Algunas reflexiones sobre informalidad y regularización del suelo urbano. Revista Bitácora Urbano Territorial, 14(1), pp. 63-88.

CRAVINO, C. (2013). Construyendo barrios. Transformaciones socioterritoriales a partir de Programas Federales de Vivienda en el Área metropolitana de Buenos Aires (2004-2009). Polis, Revista Latinoamericana, 12(36), pp. 539-544.

DI VIRGILIO, M. M. (2015). Urbanizaciones de origen informal en Buenos Aires. Lógicas de producción de suelo urbano y acceso a la vivienda. Estudios demográficos y urbanos, 30(3), pp. 651-690.

FANK, L. (2019). Promoción Industrial e Informalidad urbana en Tierra del Fuego: análisis histórico comparativo. Revista F@ro, 2(30),pp. 138-162.

FERNANDES, E. (2016). Consideraciones generales sobre las políticas públicas de regularización de asentamientos informales en América Latina. En Derecho a la Ciudad. Sinjusticia social urbana no hay ciudadanía. Revista Institucional de la Defensa Pública, (10), pp. 86- pp. 97. https://www.mpdefensa.gob.ar/ sites/default/files/revista_n_10_derecho_a_la_ciudad.pdf

GÓMEZ, J. A., GUTIÉRREZ, J. C., \& AJÁ, A. H. (2014). La vulnerabilidad urbana en España. Identificación y evolución de los barrios vulnerables. Empiria. Revista de metodología de ciencias sociales, (27), pp. 73 - pp. 94. 
HABITAT, UN (2015). Informal Settlements (Habitat III Issue Paper 22). UN Habitat.

HERZER, H., DI VIRGILIO, M., RODRÍGUEZ, C., \& REDONDO, A. (2008). ¿Informalidad o informalidades?: Hábitat popular e informalidades urbanas en áreas urbanas consolidadas. Pampa: Revista Interuniversitaria de Estudios Territoriales, (4), pp. 85-112.

INDEC (2010). Censo Nacional de Población, Hogares y Viviendas 2010, Buenos Aires, INDEC. https://www.indec.gob.ar/ftp/cuadros/poblacion/censo2010_tomo1. pdf

JARAMILLO, M. (2008). Reflexiones sobre la Informalidad fundiaria como peculiaridad de los mercados de suelo en América Latina. Revista Territorios, N. $^{\boldsymbol{o}}$ 18-19, pp. 11-53. Bogotá.

KATZMAN Rubén (1999). Marco conceptual sobre activos, vulnerabilidad y estructura de oportunidades. CEPAL.

LEFEBVRE, H. (2017). El derecho a la ciudad [1968]. Capitán Swing.

MARTÍNEZ, S. (2017). Modelo de proyección de necesidades basado en dinámicas demográficas, para la gestión integral del hábitat. Informe final Subsecretaría de Planificación Territorial de la Inversión Pública. Gobierno de la Provincia de Tierra del Fuego, AIAS.

MASTROSCELLO, M. A. (2008). La economía del fin del mundo: configuración, evolución y perspectivas económicas de Tierra del Fuego. Editorial De los Cuatro Vientos.

ONU-HABITAT (2019). Elementos de una vivienda adecuada. https://www.onuhabitat.org. mx/index.php/elementos-de-una-vivienda-adecuada

PÍNGARO LEFEVRE, C.; REESE, E.; BRESCIA, F.; BASUALDO, G.; MIGUENS, L.; TUFRÓ, M. \& PERELMAN, M. (2016). Vulneraciones de derechos en tomas de tierra y asentamientos. Entre la necesidad, el mercado y el Estado en Derechos Humanos en la Argentina. Informe Derechos humanos en Argentina 2016. CELS.

PÍREZ, P. (2016). La urbanización ¿mercancía o derecho? Una discusión para la política urbana. En: F. Carrión y J. Erazo (Comp.), El derecho a la ciudad en América Latina. Visiones desde la política. UNAM-IDRC, pp. 219-239.

PÍREZ, P. (1995). Actores sociales y gestión de la ciudad. Ciudades. Red Mexicana de Investigadores Urbanos. 7(28), pp. 8-14.

PNUD (2006). Informe sobre Desarrollo Humano 2006. Nota técnica 1. Cálculo de los índices de Desarrollo Humano. Mundi-Prensa Libros. http://hdr.undp.org/sites/ default/files/hdr_2006_es_completo.pdf 
REESE, E. (2011). Instrumentos de gestión urbana, fortaleciendo el rol del municipio y desarrollo con equidad. Carajillo de la Ciudad. Revista Digital del Programa en Gestión de la Ciudad, Año 3, Universitat Oberta de Catalunya. https://cafedelasciudades.com.ar/carajillo/carajillo10.htm

REGUANT-ÁLVAREZ, M., \& TORRADO-FONSECA, M. (2016). El método Delphi. REIRE. Revista d'Innovació i Recerca en Educació, 9(2), pp. 87-102.

ROMO, V. Y., PARRA, C. M., \& RUCHARDT, M. D. (2017). Vulnerabilidad socio-territorial: posibilidad de determinarla a partir de una construcción metodológica. Revista Geográfica Venezolana, 58(1), pp. 148-164.

RUIZ, A. (2019). El potencial de la percepción social aplicada al análisis de la vulnerabilidad en la planificación urbana. Revista EURE (Santiago), 45(136), pp. 31-50.

SCHUSCHNY, A., \& SOTO, H. (2009). Guía metodológica. Diseño de indicadores compuestos de desarrollo sostenible. (Documento de proyectos No. 255). CEPAL, GTZ.

SMOLKA, M. \& BIDERMAN, C. (2009). Measuring informality in housing settlements: why bother? Land Lines, 21(2), pp. 14- pp. 19.

TAPELLA, E. (2007). El mapeo de Actores Claves. Documento de trabajo del proyecto Efectos de la biodiversidad funcional sobre procesos ecosistémicos, servicios ecosistémicos y sustentabilidad en las Américas: un abordaje interdisciplinario, Universidad Nacional de Córdoba, Inter- American Institute of Global Change Research (IAI). [Manuscrito inédito]. https://planificacionsocialunsj.files.wordpress.com/2011/09/quc3a9-es-el-mapeo-de-actores-tapella1.pdf

TECHO (2016). Índice de vulnerabilidad territorial. [Manuscrito inédito]. http://relevamiento. techo.org.ar/downloads/ivt_metodologia.pdf

VARELA, O. \& CRAVINO, M. C. (2008). Mil nombres para mil barrios. Los asentamientos y villas como categorías de análisis y de intervención. En Cravino, M. C. (Org.), Los mil barrios (in)formales. (pp. 45-64). Universidad nacional de General Sarmiento.

VILLASMIL, J. D. (2013). La Vulnerabilidad urbana: un enfoque ambiental y sistémico. En Urbana 1(1). http://saber.ucv.ve/ojs/index.php/rev_urb/article/ view/9881/9693

YAÑEZ ROMO, V. \& MUÑOZ PARRA, C. (2017). Construcción metodológica para determinar la vulnerabilidad socio-territorial frente a la pobreza. Estudios Geográficos (LXXVIII). pp. 339- 372. 
Artículos 